\title{
Phylogenetic and spatial distribution of evolutionary diversification, isolation, and threat in turtles and crocodilians (non-avian archosauromorphs)
}

Timothy J. Colston ${ }^{1,2^{*+}}$ (D) Pallavi Kulkarni ${ }^{3}$, Walter Jetz ${ }^{4,5}$ and R. Alexander Pyron ${ }^{1+}$

\begin{abstract}
Background: The origin of turtles and crocodiles and their easily recognized body forms dates to the Triassic and Jurassic. Despite their long-term success, extant species diversity is low, and endangerment is extremely high compared to other terrestrial vertebrate groups, with $\sim 65 \%$ of $\sim 25$ crocodilian and $\sim 360$ turtle species now threatened by exploitation and habitat loss. Here, we combine available molecular and morphological evidence with statistical and machine learning algorithms to present a phylogenetically informed, comprehensive assessment of diversification, threat status, and evolutionary distinctiveness of all extant species.

Results: In contrast to other terrestrial vertebrates and their own diversity in the fossil record, the recent extant lineages of turtles and crocodilians have not experienced any global mass extinctions or lineage-wide shifts in diversification rate or body-size evolution over time. We predict threat statuses for 114 as-yet unassessed or datadeficient species and identify a concentration of threatened turtles and crocodilians in South and Southeast Asia, western Africa, and the eastern Amazon. We find that unlike other terrestrial vertebrate groups, extinction risk increases with evolutionary distinctiveness: a disproportionate amount of phylogenetic diversity is concentrated in evolutionarily isolated, at-risk taxa, particularly those with small geographic ranges. Our findings highlight the important role of geographic determinants of extinction risk, particularly those resulting from anthropogenic habitat-disturbance, which affect species across body sizes and ecologies.

(Continued on next page)
\end{abstract}

\footnotetext{
* Correspondence: tim@maddreptiles.com

${ }^{\dagger}$ Timothy J. Colston and R. Alexander Pyron contributed equally to this work.

'Department of Biological Sciences, The George Washington University, Washington, DC 20052, USA

2Present address: Department of Biological Science, Florida State University, Tallahassee, FL 32304, USA

Full list of author information is available at the end of the article
}

(C) The Author(s). 2020 Open Access This article is licensed under a Creative Commons Attribution 4.0 International License, which permits use, sharing, adaptation, distribution and reproduction in any medium or format, as long as you give appropriate credit to the original author(s) and the source, provide a link to the Creative Commons licence, and indicate if changes were made. The images or other third party material in this article are included in the article's Creative Commons licence, unless indicated otherwise in a credit line to the material. If material is not included in the article's Creative Commons licence and your intended use is not permitted by statutory regulation or exceeds the permitted use, you will need to obtain permission directly from the copyright holder. To view a copy of this licence, visit http://creativecommons.org/licenses/by/4.0/ The Creative Commons Public Domain Dedication waiver (http://creativecommons.org/publicdomain/zero/1.0/) applies to the data made available in this article, unless otherwise stated in a credit line to the data. 


\begin{abstract}
(Continued from previous page)
Conclusions: Extant turtles and crocodilians maintain unique, conserved morphologies which make them globally recognizable. Many species are threatened due to exploitation and global change. We use taxonomically complete, dated molecular phylogenies and various approaches to produce a comprehensive assessment of threat status and evolutionary distinctiveness of both groups. Neither group exhibits significant overall shifts in diversification rate or body-size evolution, or any signature of global mass extinctions in recent, extant lineages. However, the most evolutionarily distinct species tend to be the most threatened, and species richness and extinction risk are centered in areas of high anthropogenic disturbance, particularly South and Southeast Asia. Range size is the strongest predictor of threat, and a disproportionate amount of evolutionary diversity is at risk of imminent extinction.
\end{abstract}

Keywords: Extinction, EDGE, Diversification, Machine learning, Conservation

\section{Background}

Turtles and crocodilians (extant non-avian Archosauromorpha) are among the most charismatic and widely recognized of all living things [1]. The stem lineages of both groups date to the Triassic, and exhibit highly derived, yet highly conserved body forms among extant species. Crocodilians are famous for their extraordinary size (up to $6 \mathrm{~m}$ and $1000 \mathrm{~kg}$ ), long snouts and tails, and bony armor under the skin; and turtles for their bony or cartilaginous shell, and the size of some marine and terrestrial species $(1.4 \mathrm{~m}$ and $400 \mathrm{~kg}$ on land, $2 \mathrm{~m}$ and 1000 $\mathrm{kg}$ in the sea). Both groups are well-represented in the fossil record and previously attained even more massive sizes and incredible diversities in shape that are not reflected in present-day species [2]. Crocodyliforms such as Sarcosuchus [3] grew up to $12 \mathrm{~m}$ and $8000 \mathrm{~kg}$, while the extinct turtle Archelon [4] reached $5 \mathrm{~m}$ and $2200 \mathrm{~kg}$. In comparison to their terrestrial vertebrate relatives (birds, mammals, reptiles, and amphibians), both groups have very few living species $(\sim 360$ turtles and $\sim 25$ crocodilians), and a large proportion of extant species are both highly evolutionarily distinct [5] and highly endangered [6,7], with the Madagascan Big-Headed Turtle (Erymnochelys) having the highest EDGE score of any terrestrial vertebrate [5].

Turtles and crocodilians present several interesting hypotheses regarding historical diversification. First, the group exhibits relative global constancy in the fossil record during the Cretaceous-Paleogene extinction [8-13]. In contrast, there are significant fossil data indicating local extinctions in numerous turtle groups through time $[14,15]$. Therefore, we test if there is any signature of a K-Pg global mass-extinction event or shift in lineage-wide diversification rates either prior or subsequent to the K-Pg boundary. Such a pattern may be relevant if extinction risk is concentrated in older or younger taxa, or in particular lineages crossing the boundary.

Second, stem-group turtles and crocodyliforms date to the Triassic, where morphological disparity is much higher, with a greater diversity of body forms in fossil species than observed today $[16,17]$. Thus, we test if significant shifts in body-size evolution are detectable among extant lineages of turtles and crocodilians as found in some previous studies $[18,19]$, in comparison to the drastic variation seen in their fossil relatives $[16,17]$. If observed, we hypothesize that such shifts may offer partial explanations for the present-day apportionment of ED and thus extinction risk among species, particularly if body size is related to threat status as in amphibians [20], birds [21], mammals [22, 23], and squamates [24].

Despite their visibility as wildlife and study organisms, to date there have been no taxonomically complete, dated phylogenies produced for turtles and crocodilians. Such trees are invaluable for quantifying the evolutionary distinctiveness of extant species [25, 26], testing hypotheses about historical rates of diversification and body-size evolution [27, 28], predicting threat status for data-deficient (DD) and unassessed (UA) species [20, 29], and quantifying the spatial and phylogenetic distribution of extinction risk [30, 31]. The latter two aims are particularly crucial given the higher proportion (65\% of all species) of threatened turtles and crocodilians [32] compared to groups such as amphibians with 33-50\% threatened [20], mammals $\sim 25 \%$, birds $\sim 12 \%$, and squamate reptiles $\sim 12 \%$ based on the most recent assessments [33]. A recent study estimated and imputed ED and EDGE scores based on available phylogenetic datasets [5], but the scanty taxonomic coverage of the trees and the imputation methods employed by those authors leaves a wide margin for error.

Here, we use taxonomically complete, dated phylogenetic estimates to calculate ED from "fair proportion," a measure of the evolutionary isolation of each species and correlate of net diversification rates [25]. Species with high ED represent relict lineages on long branches, whereas groups of low-ED species represent more recent, rapid radiations; ED is thus correlated with and reflects historical diversification patterns, in the branch lengths of extant species [34]. These data are invaluable for identifying conservation priorities [35], given the necessity of triage when allocating limited resources for management and further research [36]. Indeed, at least 
nine species of turtles are thought to have gone extinct in modern times [37], a higher percentage (2.5\%) than birds (1.9\%), mammals (1.7\%), amphibians $(0.4 \%)$, or squamate reptiles $(0.2 \%)$ among terrestrial vertebrates which have been assessed [33], while dozens more turtles and crocodilians are critically endangered throughout the world [38].

Second, we gather spatial and trait data for all species to identify the key factors related to extinction risk and build predictive models to estimate threat status for DD and UA species [29,39]. While $23 / 27$ crocodilians have been assessed (85\%) of which 11 are threatened (48\%), only $258 / 357$ turtles $(72 \%)$ have been assessed, of which 182 are threatened (71\%). Thus, half to two-thirds of all assessed crocodilian and turtle species are threatened, but a quarter of all species are without robust assessment or prediction [38]. Many crocodilians and turtles have traits making them particularly susceptible to anthropogenic threats such as small geographic ranges [40], long generation times [41], exploitation for food and commerce [42], reliance on fragile habitats such as coastlines [43], and occurrence near human-population centers such as South and Southeast Asia, the eastern Nearctic, and coastal Australia [38]. We use a variety of statistical and machine-learning methods to identify the strongest correlates of known extinction risk and predict threat statuses for the remaining DD and UA species $[20,44]$.

These data allow us to answer several pressing questions regarding extinction risk at the global scale. Is evolutionary distinctiveness related to threat status? No such pattern exists for birds [26], mammals [45], amphibians [31], or squamate reptiles [46], albeit with limited data for some of these groups. However, many lineages of turtles such as the Fly River or Pig-Nosed Turtle (Carettochelys) and the Big-Headed Amazon River Turtle (Peltocephalus) are known to be threatened and occupy isolated phylogenetic positions [38, 47]. In contrast, the most ancient crocodilian species [48] are the alligators (Alligator), for which the American Alligator is Least Concern, while the Chinese Alligator is Critically Endangered [33]. Which are the most distinct and endangered species when combining ED and threat status [5]? In terms of spatial distribution, are there geographic hotspots of concentrated threat [40], or geographic "arks" with high diversity of non-threatened species and improving human footprint [49]?

In contrast to the massive variation seen across the fossil record of turtles and crocodyliforms, the phylogeny of extant species shows little evidence for mass extinctions, changes in diversification rate, or shifts in bodysize evolution; although the lack of detectable shifts in body-size evolution is likely limited by sampling extant species. Unlike all other terrestrial vertebrates, we find that extinction risk is concentrated non-randomly among the most distinct and unique species, a worrying pattern that suggests current trends will erase a disproportionate amount of evolutionary history. These risks are concentrated both in specific lineages and particular geographic areas, while other clades and regions represent relative havens for diversity. Together, these data paint a picture of urgency for the conservation of select species of high distinctiveness and high extinction risk.

\section{Results}

\section{Phylogeny and diversification}

All data and results, including the tree topology with support values (Appendix S1), are available in the SI text and DataDryad (https://datadryad.org/review?doi=doi:1 $0.5061 /$ dryad.h19t7b2). Our phylogeny is robust overall, with monophyly of all families, subfamilies, and genera strongly supported. Of particular note is the continued weak support for relationships in the tortoise family Testudinidae (but see [50]), as well as broader uncertainty in higher-level relationships among and placement of Cheloniidae, Chelydridae, Emydidae, and Platysternidae [47, 51-53].

We recover a unique topology from these previous four analyses, with successive divergences of Chelydridae+Dermatemydidae+Kinosternidae, Cheloniidae+Dermochelyidae, Platysternidae, Emydidae, and Testudinidae+Geoemydidae [54]. This is based on the same or similar underlying datasets and may reflect issues such as mito-nuclear discordance and phylogenetic signal in the available loci. However, our increase in both taxon and characters sampling may indicate convergence on a more robust topology. Future analyses sampling more loci may be able to resolve these relationships with greater support.

Several turtle clades have been identified by previous authors $[18,19,51]$ as representing extraordinary instances of evolutionary diversification, including Galapagos tortoises (Chelonoidis), and New World emydids (Deirochelyinae). Similar results were recovered in our preliminary analyses. However, we believe strongly that these are artifactual, and represent an inconsistent application of species concepts and delimitation in turtles. At the current juncture, we are constrained by existing taxonomic frameworks, and these issues must thus be left to future studies. However, interpretation of our downstream results (see below) should be colored by knowledge of these issues. We attempt, when possible, to use analyses and interpret models in a way that is resilient to the possibility of low-level taxonomic biases.

Results for turtles and crocodilians showed roughly constant rates of speciation and extinction, with no support for any shifts therein, or any global mass-extinction events (Fig. 1a). Turtles exhibit speciation rates of $\sim 0.07$ 
lineages per million years and extinction rates of $\sim 0.03-$ 0.04 , for net diversification of $\sim 0.03-0.04$ and turnover probabilities of $\sim 43-57 \%$ from the Jurassic to the present. For crocodilians, rates are $\sim 0.05$ and $\sim 0.02$ respectively, for net diversification of $\sim 0.03$ and turnover of $\sim 40 \%$ from the Cretaceous to the present.

For body size, few strongly supported jumps are estimated by the model for branches subtending extant taxa (Fig. 1b). Thus, most variation can be attributed to steady drift over time for living species, in contrast to ecomorphologically diverse fossil relatives [16, 17]. One jump occurs along the stem branch leading to crocodilians, reflecting the difference in body size between the two groups, crocodilians being longer and heavier on average. A second occurs in the relict species Carettochelys insculpta, a large freshwater species, which is the sister lineage of the radiation of softshell turtles (Cyclanorbinae and Trionychinae) that contains both large and medium sized species. Three terminal species are also estimated as jumps, each of which is significantly smaller than its congeners. These are Pelodiscus parviformis, Pseudemys gorzugi, and Trachemys adiutrix. As noted above, these radiations have questionable species boundaries [55-57], and we refrain from interpreting these results further.

\section{ED and threat status}

We find a bi-modal distribution of ED values for extant turtles (Fig. 2). The primary mode is $17 \mathrm{Ma}$, older than amphibians at $16.5 \mathrm{Ma}$ [31], squamate reptiles at $11 \mathrm{Ma}$ [46], birds at $6.2 \mathrm{Ma}[26,28]$, or mammals at $4.8 \mathrm{Ma}$ [58]. A secondary mode at $5 \mathrm{Ma}$ is dominated by the recent "radiations" in Deirochelyinae and Testudininae (see Discussion), for which multi-locus nuclear datasets generally do not support the higher number of morphologically delimited lineages. Thus, we refrain from examining among-lineage rate variation for speciation or extinction.

Across the three methods for threat-status imputation, the final predictions for the 114 species are fairly similar (Appendix S5), with all models identifying area as the single-most important variable by far (Figs. S7-13), as in amphibians [20], birds [59], mammals [60], and squamate reptiles [24]. Each method picked out slightly different contributions from secondary predictors. The second-ranked variable for the PGLM model was occurrence in the Oriental ecoregion; for the RF model there is a tie between AET (ecology) and HEI (anthropogenic disturbance); and for the ANN model it was spatial dissimilarity, indicating the geographic clustering of threat status (see below). Body size (length or mass) were not particularly important, unlike for amphibians [20], birds [21], mammals [22, 23], and some squamates [24, 61]. Training accuracy for the three models was higher
$(\mathrm{PGLM}=38 \%, \quad \mathrm{RF}=49 \%, \quad \mathrm{ANN}=48 \%) \quad$ than random (17\%) and confusion matrices showed high sensitivity and specificity (up to $86 \%$ ), with errors usually involving only a single step in either direction.

Overall, 21 species were predicted identically by all three approaches, and 69 agreed for two out of the three, for $\sim 79 \%$ concordance overall. On a pairwise basis for 342 comparisons (114 species times three models), 141 were identical (41\%) and an additional $144(42 \%)$ were adjacent (one category different), for a total of $83 \%$ identical or adjacent predictions. Given the high level of agreement and lack of apparent bias towards higher or lower categories for any model, we simply used the mean of the three predictions for our final estimate of threat status.

Our final estimate included 17 species classified as LC, $27 \mathrm{NT}, 47 \mathrm{VU}, 15 \mathrm{EN}$, and $8 \mathrm{CR}$. Imputed statuses showed a similar distribution of ED to known species (Fig. S14). Qualitatively, the imputed species were heavily concentrated in tropical pleurodiran lineages, particularly those with many recently described or resurrected species such as Pelusios [62] and Pelomedusa [63]. Nearly all of the primarily sub-Saharan African pelomedusines, and $\sim 2 / 3$ of the primarily Australasian chelodinines were imputed. No other subfamily with more than 2 species had fewer than $50 \%$ assessments. The final breakdown of assessed + imputed threat statuses used for subsequent analyses was $71 \mathrm{LC}, 61 \mathrm{NT}, 119 \mathrm{VU}, 63$ EN, $61 \mathrm{CR}$, and 9 EX. Thus, $66 \%$ of modern turtle and crocodilian species are threatened or extinct.

Comparing ED across threat statuses (Fig. 3), nonthreatened species (LC, NT) have significantly lower median ED (18 Ma vs. $21 \mathrm{Ma}$ ) than threatened species (VU, EN, CR), using a two-sample $t$-test $(t=-2.2, P=0.03)$. This is driven primarily by the higher median ED of VU and CR taxa, while EN covers a broad range of highand low-ED species (Fig. 2). Thus, imminent extinction of threatened species would represent a disproportionate loss of total evolutionary history across crocodilians and turtles, preferentially removing unique and derived lineages from the Tree of Life, indicating their moreprecarious stature in the conservation landscape compared to other terrestrial vertebrates such as amphibians.

Combining the ED and threat statuses to calculate EDGE scores indicating the intersection of distinctiveness and risk, we highlight the top-10 at-risk turtles and crocodilians (Fig. 4; Table S1). These data also indicate that the highest-ranked turtles exceed crocodilians in their combination of ED and threat. We find that our estimated ED scores are similar to those from [4] when estimated directly from their phylogenetic dataset, but that a large cluster of their imputed values appear to be inflated (Fig. S15). Estimated EDGE scores are more similar between the two datasets, but variation in ED led 

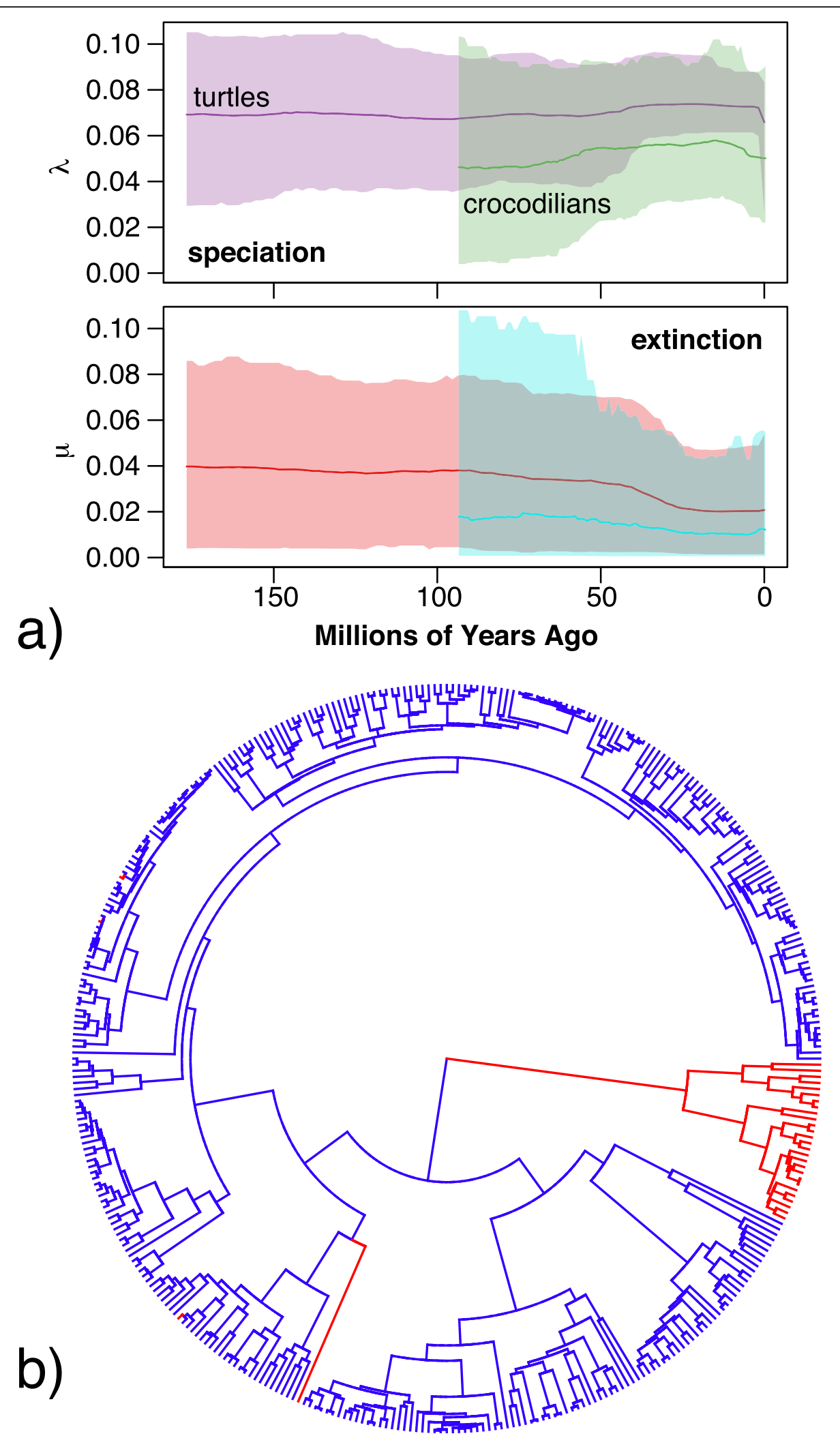

Fig. 1 Results from (a) TESS/COMET analysis showing estimated speciation and extinction rates for turtles and crocodilians across time; and (b) location of significant jumps (red) inferred under a Lévy process in crocodilians, Carettochelys, and three other species 


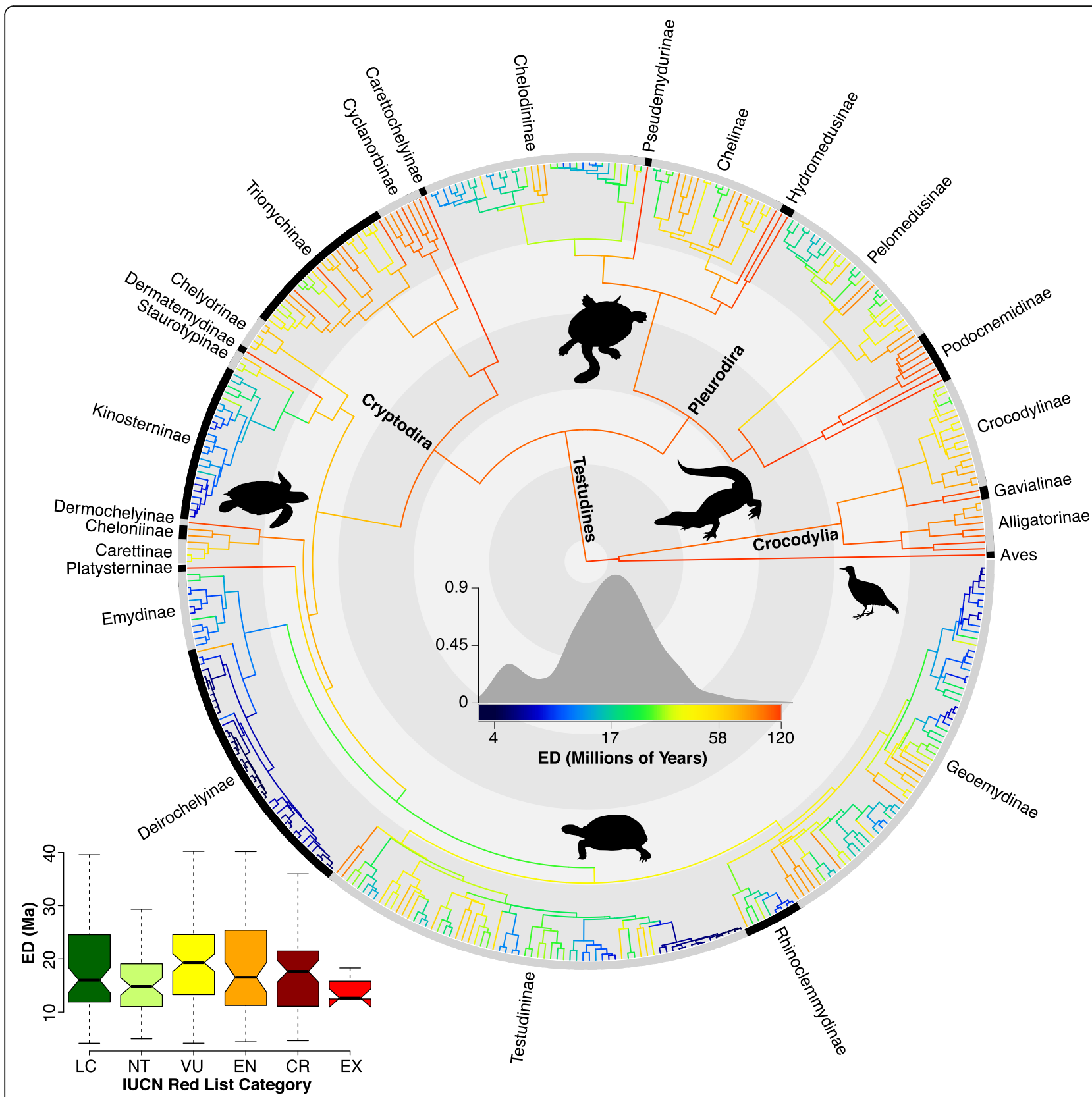

Fig. 2 Randomly-selected phylogeny, with branches colored proportional to ED for extant lineages. The internal contrasting rings denote $50 \mathrm{Ma}$ intervals. The insets show the overall distribution of ED across 356 turtle and 27 crocodilian species, and the distribution of ED across threat statuses, including both assessed and imputed species. Silhouettes are from http://ww.phylopic.org/; see Supplemental Information for license details

previous authors to overemphasize some taxa (such as sea turtles; Cheloninae) and underemphasize others (such as flapshell turtles; Cyclanorbinae). Our dataset thus provides a more robust and presumably more accurate picture of ED and EDGE in the group (see Table S1).

\section{Geography of threat}

Geographically, threatened taxa are concentrated in a few major sub-areas [38] of the 11 global ecoregions
[47]. The highest diversity of threatened species occurs in South and Southeast Asia in the Red, Mekong, Irawaddy, and Ganges-Brahmaputra River deltas and Peninsular Malaysia (Fig. 5a). Secondary hotspots occur in tropical western Africa, and the eastern Amazon River basin. In contrast, "arks" of non-threatened species are observed in the eastern Nearctic, Australia-New Guinea, eastern Africa, and the western Amazon River basin (Fig. 5b). We note that the prominence of the eastern 


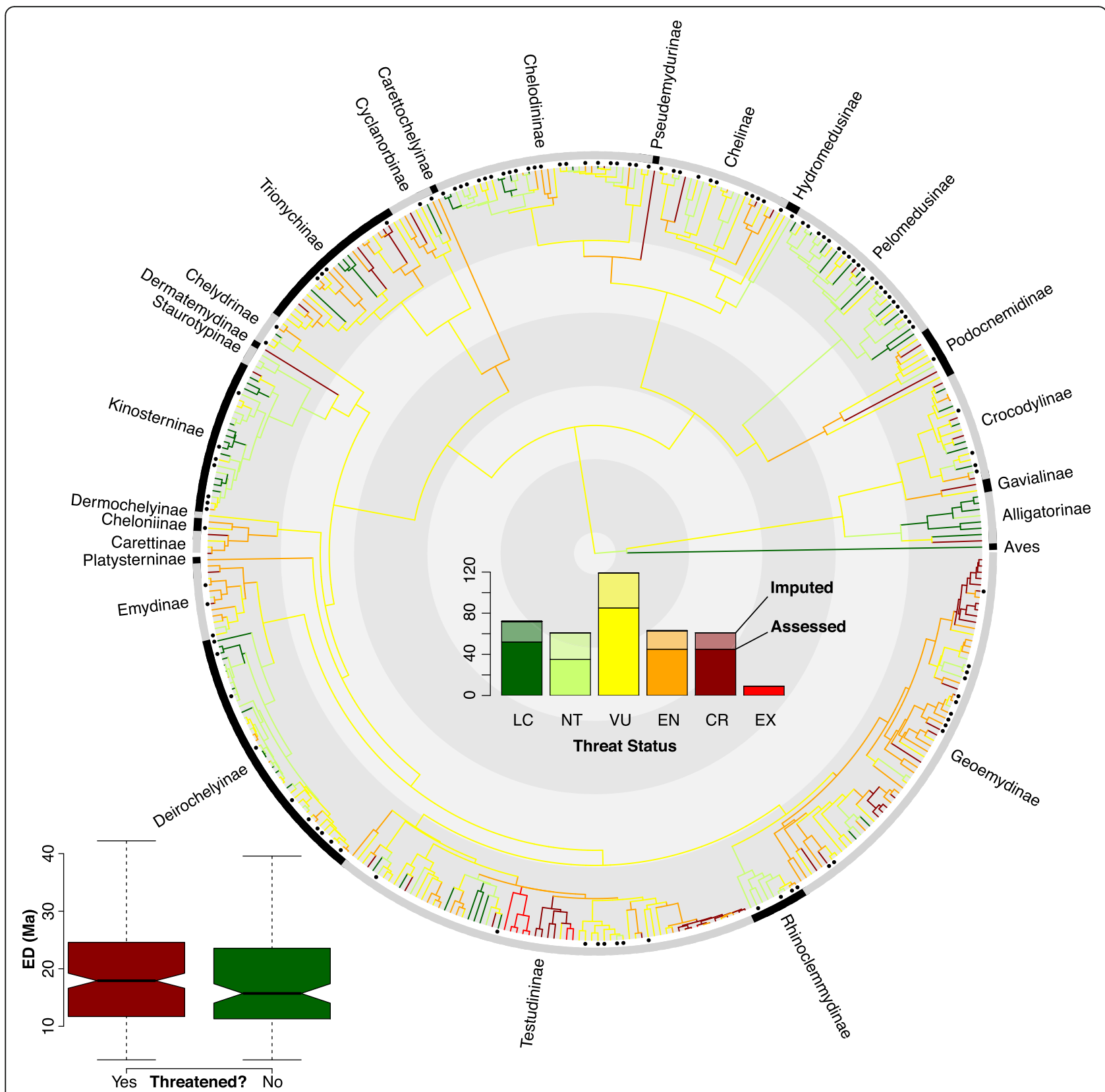

Fig. 3 Randomly-selected phylogeny, with branches colored according to threat status for all species; imputed statuses are indicated with a tip marker. The internal contrasting rings denote $50 \mathrm{Ma}$ intervals. The insets show the overall distribution of threat statuses (assessed are solid and imputed are transparent), and the distribution of ED across threatened vs. non-threatened, including both assessed and imputed species

Nearctic is reduced when species richness is weighted by EDGE scores (Fig. S4), accounting for the low distinctiveness of the high number of questionably delimited deirochelyine species in that area. Interestingly, there are also modest concentrations of non-threatened species $(\sim 5-10)$ in the Ganges-Brahmaputra River delta and the Yucatan peninsula, both regions characterized by several high-ED threatened species (Figs. 4 and 5). Finally, island endemicity is not a strong predictor of threat status from any of the models, and regions such as Madagascar and the Philippines that have flagship high-ED threatened species (Table S1) nevertheless don't represent concentrated hotspots of threat.

\section{Discussion}

Phylogeny and diversification

Our topological results are closely aligned to previous work on turtles and crocodilians [18, 47, 48, 51-53] but offer a new time-calibrated perspective on the tempo and mode of evolutionary diversification and the 


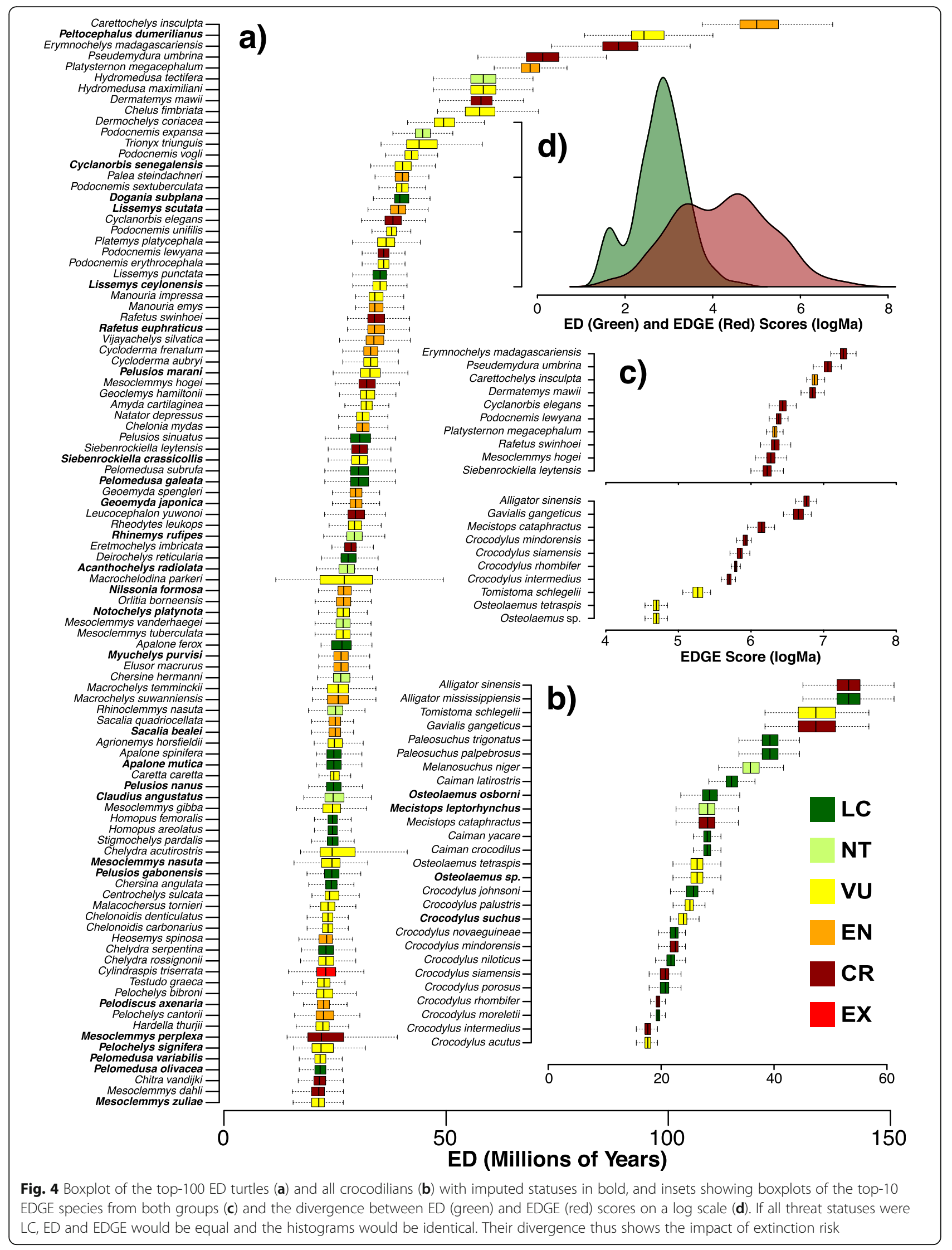




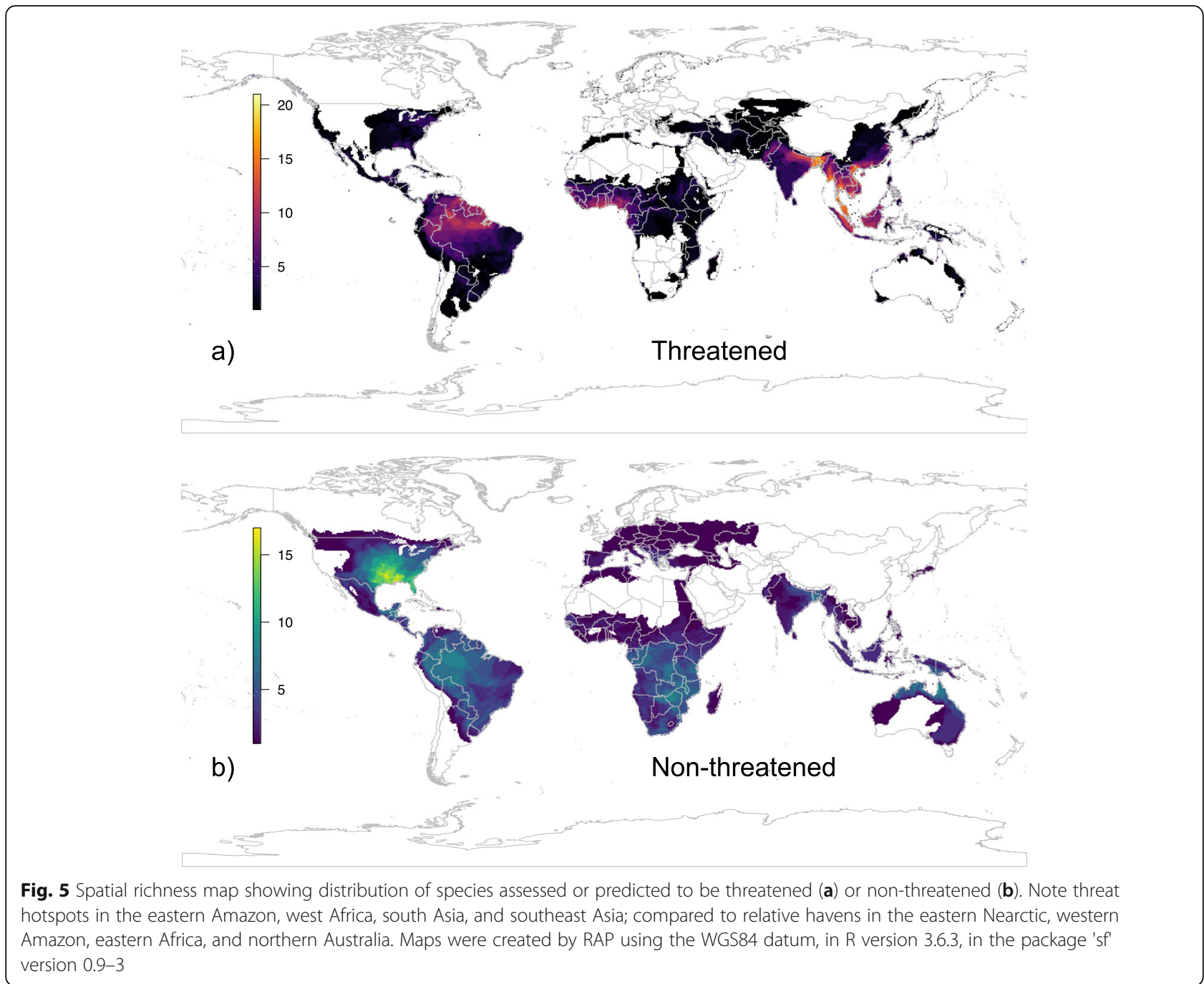

phylogenetic and spatial distribution of extinction risk (Figs. 2, 3, 4 and 5). Our estimate of turtle and crocodilian phylogeny is the most complete to date, with $95 \%$ of extant species sampled for up to $\sim 21 \mathrm{~kb}$ (Fig. 2). However, it is far from the last word on the subject, and we suspect that our (and previous) results are beset by confounding factors such as voucher identification [52], poorly defined species boundaries $[64,65]$, proper identification of targeted sequencing regions $[66,67]$, and mito-nuclear discordance $[68,69]$.

We attempted to alleviate these issues by selecting well-characterized voucher specimens, but errors may still remain. We are generally confident in strongly supported relationships to the genus level, but caution that some species-level relationships may reflect the problems listed above. Similarly, as only 17 species required imputation, strong support for the monophyly of most genera provides at least preliminary confidence for the placement of imputed species. Overall, we consider the general concordance of our results with previous estimates to provide a sufficient basis for broad-scale analysis of global patterns, particularly with respect to biogeography, diversification, macroecology, and spatial distributions of extinction risk.

However, most turtle genera have not yet been subject to modern systematic revisions in an integrative taxonomic framework that combines morphological and molecular data with explicit criteria for delimiting species [70, 71]. For instance, [65] showed that the eight traditionally recognized species of Pseudemys reduced to only three species-level lineages in their molecular analyses. Similarly, [72] showed that the 14 currently recognized species of Graptemys, long noted for their low levels of molecular divergence [95], appeared to represent eight or nine species-level lineages at most. These findings were confirmed [73] by authors who nevertheless continued to recognize 14 species. Similar instances of mismatches in the level of mitochondrial, nuclear, and morphological divergence have been noted in Trachemys [74] and Cuora [64, 67]. In the Galapagos, nearly 
every island has a "species" of Chelonoidis that can putatively be diagnosed morphologically, but these have exceptionally low genetic divergence, and often interbreed and produce viable hybrids [75, 76]. Many other apparently valid species of turtle (e.g., Cuora) also appear to hybridize naturally, in the wild, with great frequency [77, 78]. Drastically reducing the number of recognized turtle species as indicated by molecular data in many lineages would likely decrease rate estimates and the prominence of clades such as Chelonoidis and Deirochelyinae in phylogenetic comparative analyses.

Consistent with the evolutionary durability and morphological conservatism of extant lineages [8-13], both turtles and crocodilians exhibit roughly constant rates of speciation and extinction across time, with no evidence for any significant global mass-extinction events in the molecular phylogeny (Fig. 1a). This is unlike birds [28], mammals [58], amphibians [31], and squamate reptiles [79], which show strong evidence for shifts in diversification rate or mass-extinction events coincident with the K-Pg boundary.

Similarly, extant turtles and crocodilians are defined by a single-rate background Brownian motion process of body-size evolution, with little evidence for significant among-lineage variation in rates, a few singleton species excepted (Fig. 1b). This contrasts with fossil data suggesting localized extinction events and drastically higher morphological disparity for some lineages, particularly in the Mesozoic [13, 14]. Given the richness of the turtle and crocodylomorph fossil record [80, 81] and the potential limitations on estimating past diversity dynamics in these groups from the evolutionarily limited sampling of extant taxa [82] we suggest this is a rich area of future study incorporating tip-dated phylogenies of fossils and extant taxa [83].

\section{Threat status}

In contrast to diversification rates and body size, ED and threat status show strong associations and non-random patterns in their evolutionary distribution (Figs. 2, 3 and 4). Groups such as Alligatorinae (alligators and caimans), Podocnemidinae (South American river turtles), and Cyclanorbinae (flapshell turtles) are generally comprised of highED (>50 Ma) species, while Kinosterninae (mud turtles) and Deirochelyinae (map turtles and sliders) consist almost entirely of low-ED (<17 Ma) species. With regard to threat, groups such as Geoemydinae (Asian box turtles) and Testudininae (tortoises) are almost all threatened, while Pelomedusinae (African side-necked turtles) along with Kinosterninae and Deirochelyinae have a low proportion of threatened species. This pattern also yields a significant association between ED and extinction risk (Figs. 2 and 3); loss of currently threatened taxa would represent a disproportionate loss of evolutionary history in the group, far more so than in any other terrestrial vertebrate lineage.

A majority (66\%) of turtle and crocodilian species are threatened, resulting from a number of factors including organismal traits and anthropogenic factors. By far the most important variable affecting extinction risk is the total geographic area covered by a species' range, as in amphibians [20], birds [59], some mammals [60], and squamate reptiles [24]. The effect of small ranges on extinction risk is due in large part to smaller population sizes $[84,85]$ and is likely amplified in turtles and crocodilians by their conspicuous nature [86], long generation times [87], and high degree of human exploitation [6]. For instance, amphibians and squamate reptiles with small ranges also tend to be threatened, but primarily due to ecological and demographic effects [20, 24]. For squamates, human persecution or exploitation for food or commerce is generally limited to a few larger species (e.g., South American tegus and African bullfrogs) and not a common threat for the majority of taxa.

An additional critical factor facing turtles and crocodilians is the spatial distribution of their diversity; perhaps more so than for any other group of terrestrial vertebrates, "geography is destiny." Birds, mammals, amphibians, and squamate reptiles exhibit massive speciesrichness in sparsely populated tropical areas such as the Amazon and Congo river basins, the Andes mountains, and the Greater Sunda Islands [88]. In contrast, while there are some turtle and crocodilian species in those areas, their peak species-richness (Fig. 5) is coincident with the highest population-density and strongest exploitation pressures on the planet, in South and Southeast Asia [40]. Concomitantly, our PGLM model identifies occurrence in the Oriental ecoregion [42] as the second-strongest predictor of threat status behind area. Similar effects are seen in other heavily deforested and densely populated tropical regions such as western Africa and the eastern Amazon river basin [89]. In contrast, areas such as Australo-Papua, eastern Africa, the western Amazon, and the Nearctic have lower population densities and less deforestation [49] and exhibit higher richness of non-threatened species (Fig. 5b).

A final pattern of great importance is that, despite the high concentration of threat in particular geographic regions such as the Indo-Gangetic plain [40], the distribution of species with the greatest combination of ED and threat (so-called 'EDGE' species [5]) is far more dispersed and idiosyncratic (Fig. S4, Table S1). This reflects the ancient history of both groups, across numerous tropical and temperate landmasses and remote oceanic islands [47]. The top-10 turtle taxa by EDGE score include species from Madagascar (Erymnochelys), Papua New Guinea (Carettochelys), and the Philippines (Siebenrockiella), along with Africa, Asia, Australia, and South 
America. Similarly, the top-10 crocodilians by EDGE score are found in South and Southeast Asia, Africa, Indonesia and the Philippines, the Caribbean, and South America. Thus, while the bulk of diversity is concentrated and threatened in particular geographic hotspots (such as South and Southeast Asia), exceptionally distinct and threatened species are found outside of these areas in other global regions of high extinction risk.

\section{Conclusions}

Here, we provide a blueprint for guiding conservation management of these threatened taxa, highlighting both specific geographic areas with a high concentration of extinction risk, and exceptionally distinct and threatened species worldwide (Figs. 2, 3, 4 and 5). On the upside, given the relatively small number of species involved, their charisma, and the attendant amount of attention they receive, robust conservation-management plans and long-term restoration strategies are already in place for many turtles [7, 38] and crocodilians [7, 90]. On the downside, while some of the "ark" areas such as the eastern Nearctic, Yucatan, and eastern Africa are improving in terms of human footprint [49], anthropogenic pressures show no signs of slowing or reversing in many of the global hotspots identified here such as South and Southeast Asia, western Africa, and tropical South America [91].

\section{Methods}

\section{Phylogeny construction}

Detailed materials and methods for all data and analyses are available in the SI text. We used well-established methods for supermatrix estimation and taxonomic imputation to create a posterior distribution of trees containing full taxonomic sampling for turtles and crocodilians [28, 31, 46, 92]. Using the 8th edition of Turtles of the World [37], we recognized 357 species of extant or recently extinct turtle. Based on several recent references, we recognized 26 described crocodilian species plus one undescribed Osteolaemus from Western Africa [93]. We sampled 14 mitochondrial loci; 12S, 16S, ATP6, ATP8, COI, COII, COIII, CYTB, DLOOP, ND1, ND2, ND3, ND4, and ND5; and six nuclear loci; BDNF, CMOS, GADPH, ODC, RAG1, and RAG2, for all taxa. We sampled R35 for turtles only, as the intron has not been widely sequenced in other groups. This yielded 7 total nuclear loci, and 21 genes overall. Sequence data were available for 340 of 357 turtles, all crocodilians, and the two outgroups. The matrix was $24,798 \mathrm{bp}$ in total, ranging from 405 to 20,929 bp per species, and averaging 8891 bp for 369 terminals. We included Gallus gallus (Aves) and Sphenodon punctatus (Lepidosauromorpha) as outgroups.
From this sparsely sampled supermatrix, we estimated a Maximum Likelihood topology in RAxML [94], which we enforced as a constraint for a PASTIS [92] run in MrBayes [95] to estimate node ages and impute the placement of the seventeen missing turtle species. Specific taxonomic information on the placement of these imputed taxa is provided in the supplemental information. We placed constraints on the ages of seven key nodes, using consensus age-estimates from the Time Tree of Life database (see supplement). We estimated the clock-rate prior using standard approaches [96] and used a pure-birth model for the branch-length priors to remain conservative with respect to the historical signature of extinction [28].

This approach yielded a posterior distribution of 10 , 000 taxonomically complete, dated phylogenies. While some authors caution against using phylogenies with imputed taxa to measure rates of character evolution [97], we note that i) the number of imputed taxa is extremely small $(17 / 384 ; \sim 4 \%)$, which should reduce any bias in estimated rates; and ii) those authors also found that estimated diversification rates provided stable inferences [98]. Thus, these phylogenies can thus be used for myriad downstream comparative analyses, such as estimating diversification regimes, predicting threat status, and testing for phylogenetic signal. We do caution that issues of taxonomic non-equivalence in species-level taxa among different turtle groups may hamper some estimates of diversification (see below \& supplement).

\section{Diversification analyses}

To evaluate temporal variation in diversification rate, we used algorithms implemented in the TESS package [99], which estimate speciation and extinction rates through time across a clade while allowing for shifts, as well as testing for global mass extinctions. We do not specify the hypothesized location of any rate shifts or mass extinctions beforehand, and the model is thus agnostic to their temporal location. However, we generally hypothesize that if significant shifts or extinction periods are observed, they would be localized near the $\mathrm{K}-\mathrm{Pg}$ boundary. Specifically, we inferred rate estimates for speciation and extinction with a Bayesian variable 'birthdeath' model [99], conditioned on turtles and crocodilians separately. Jointly with this analysis, we also searched for potential evidence of past clade-wide mass extinctions using the 'compound Poisson process on mass-extinction analysis' or 'CoMet' model [100].

We sampled ten trees from the posterior of each of the two clades and modelled a variable 'birth-death processes' with explicit mass-extinction events following the guidelines in [99], with the sampling fraction set to 1 and the expected survival of a mass extinction equal to 0.05 (95\% extinction). We generated empirical 
hyperpriors through an initial Bayesian Markov chain Monte Carlo analysis under a constant-rate birth-deathprocess model to determine reasonable hyperparameter values for the diversification priors. We allowed up to two mass-extinction events and two rate change events and set the shape parameter for the mass-extinction prior to 100; varying these parameters yielded qualitatively similar results. After burnin, we ran final analyses for 100,000 generations and diagnosed models using effective sample size (> 200 ) and the Geweke statistic. We evaluated significance of rate shifts and mass extinctions using Bayes factors, mentioning instances $>6$ and considering $>10$ strong support.

\section{Body-size evolution}

We used the program levolution, which models the rate, strength, and phylogenetic position of evolutionary jumps using a Lévy process [101]. This approach identifies saltational changes in Brownian Motion regimes in a trait across a tree [102]. These rate changes are independent across branches and can thus identify multiple uncorrelated regimes of body-size evolution across clades.

This approach has a variety of statistical, theoretical, and computational advantages over existing methods [103]. These include computational simplicity and reduced computing time, greater identifiability of parameters, and better theoretical fit to instances of rapid evolutionary bursts punctuating apparent stasis in phenotype. We only evaluated the length data (including the single imputed value for Osteolaemus sp.), as analyzing the phylogenetically imputed masses on the same phylogeny would be too circular for comfort, while the observed data alone would be too sparse for confidence in the results. For details about how these data were gathered see Trait, Spatial, and Threat Data (below) and the SI. We first estimated the value of the hyperparameter $\alpha$ using the included dynamic peak-finder algorithm, which permutes $\alpha$ until the highest likelihood is found. We used the recommended settings of 5000 sampled jump-vectors, 1000 burnin samples, and 2nd-generation thinning for the MCMC chains, and a starting value and step value of 0.5 (on a log scale), optimized 5 times. The program thus tested 14 values of $\alpha$, with 31.6228 being the final value. The LRT was significant $(D=175, P<1 \mathrm{e}-16)$, suggesting that a jump-diffusion Lévy process best fits the data. We then ran a final analysis with $\alpha$ fixed to this value, starting from the ML estimates of the mean, variance, and jump-rate parameters. For this final analysis, we increased the number of sampled vectors in the MCMC chain to 25,000 for both the parameter estimation and the jump inference, accepting jumps with posterior probabilities $>0.85$.

\section{Trait, spatial, and threat data}

For the purposes of analyzing morphological evolution and ecological correlates of extinction risk, we gathered several traits shown to be relevant in other terrestrial vertebrate groups such as birds, mammals, amphibians, and reptiles [20, 24, 29, 39, 44, 104]. Specifically, we measured body length (carapace length [CL] for turtles or total length [TL] in $\mathrm{cm}$ for crocodilians), body mass (g), microhabitat (freshwater, terrestrial, or marine), endemicity (island or mainland), biogeographic area (from 11 global ecoregions encompassing extant diversity), range size $\left(\mathrm{km}^{2}\right)$ and proximity (distance matrix of range centroids) from existing spatial datasets [88], humanencroachment index (proportion of urban or cropland in species' geographic range at $300 \mathrm{~m}$ resolution [105]), climate (BIOCLIM 36-40 measuring principal components of temperature, precipitation, and radiation at 10-min resolution [106]), and ecosystem function (mean AET and NPP from 2000 to 2015 from the MODIS datasets at $500 \mathrm{~m}$ resolution [107]).

We obtained maximum length values for all 357 turtle species and 26/27 crocodilians, and for body mass we gathered values for 202 turtle species and 23 crocodilians from exhaustive literature reviews and existing trait databases. All other data were available for all species, with the exception of BIOCLIM 36-40 for three island-endemic turtles. We imputed TL for a single species, BIOCLIM 36-40 for three species, and body mass for 159 species using phylogenetic techniques [108]. Spatial data were generated from polygon shapefiles representing the geographic range of all species, derived from published sources $[37,88,109]$ and projected globally using a World Cylindrical Equal Area projection (EPSG:54034). Overall, trait and spatial data were $>99 \%$ complete for length, area, and climate, and $\sim 70 \%$ complete for body mass, with a small number of imputed species.

For threat status, we first accessed the 29 November 2018 version of the IUCN RedList. We then changed Nilssonia nigricans from EW to CR because wild populations have recently been rediscovered [110], and assigned Aldabrachelys abrupta and A. grandidieri to EX, based on their known extinction [111]. Thus, there are 54 Least Concern, 34 Near Threatened, 72 Vulnerable, 48 Endangered, 53 Critically Endangered, 9 Extinct, and 11 Data Deficient species. These account for 258/ 357 turtles and 23/27 crocodilians, for a total of 281 assessments (270 with a known status) out of 384 total species. Remaining to impute are therefore 114 total species: 103 unassessed (99 turtles and 4 crocodilians) and 11 Data Deficient (all turtles). No species are currently Extinct in the Wild.

\section{$E D$, status, and geography}

We calculated ED of all 384 species using the 'evol.distinct (type = "fair.proportion")' function in the R package 'picante' [112] taking the median value per species across the posterior distribution of 10,000 trees. We 
then imputed the 114 DD or UA threat statuses using both traditional statistical methods [29] and novel machine-learning approaches [39]. Given the sensitivity of both types to various factors (see below), we employed one GLM-based and two ML-driven approaches to assess the variability in outcomes. This allows for reassurance that estimates are robust across methods (and thus hopefully relatively accurate), and that the previously reported strong performance of ML methods [e.g., 39] holds for new applications. First, we generated linear models [20] linking the trait, range, climatic, and ecological data to status in the 270 assessed species while including terms for phylogenetic and spatial covariance using a GLMM approach. Continuous variables were log-transformed, centered, and scaled, while categorical predictors were converted using binary one-hot (1-of- $k$ ) encoding as presence or absence of each feature. Preliminary variable selection highlighted 15 significant predictors (see supplement). We then used PGLM estimators to impute the missing statuses as a continuous estimate from 1 to 6 , corresponding to the six statuses [20, 29]. We then estimated the sensitivity and specificity of this model using leave-one-out crossvalidation, removing each of the 270 known statuses one-by-one, re-estimating them from the remaining data, and generating a confusion matrix of the known versus predicted statuses. A potential drawback of these methods results from converting a discrete multi-state class-labeled character (threat status) to a continuous variable, where outlier estimates (e.g., <0) are not biologically meaningful. Such variables are often better suited to ML techniques [39].

Second, we used the machine-learning (ML) techniques 'random forests' (RF) and 'artificial neural networks' (ANN), which have become widespread in ecology [113, 114] and conservation biology [113, 115], as implemented in the $\mathrm{R}$ package 'caret' [116]. Advantages over approaches such as GLMs include explicit applicability for predicting non-ordinal class-labeled variables (e.g., threat statuses), higher classification accuracy, greater flexibility for addressing problems such as regression and classification in a single modeling framework, and the intrinsic ability to detect and incorporate complex non-linear interactions between variables without a priori specification [113, 114]. Potential drawbacks include overfitting, ad-hoc parameterization, and "black box" estimation of variable interactions.

For the RF models, we optimized the 'mtry' variable over 500 trees including all 28 categorical and continuous predictors, plus 2-dimensional PCoA estimates of phylogenetic and spatial covariance, for a total of 32 predictors. Both ML techniques integrate out uninformative variables and are thus not particularly susceptible to overparameterization compared to classical statistical approaches such as PGLM. The RF methods are also insensitive to the relative scale of input features, which are assessed sequentially and thus do not interact, so the 32 predictors were not transformed prior to analysis. We assessed model accuracy using repeated $k$-fold crossvalidation and assessment of relative variableimportance.

For the ANN models, we used feed-forward multilayer perceptrons with a single hidden layer, trained using backpropagation under a root-mean-squared-error cost function from the 270 species with known status and the 32 categorical variables. Predictor variables were standardized as necessitated by ANNs $[113,114]$ on the interval $[0-1]$ using min-max scaling. We chose to use min-max rather than $z$-scores because we could not be assured of multivariate normality in the predictors, and min-max thus preserves the scaling of the original inputs. We tuned the model using repeated $k$-fold crossvalidation to select the number of neurons in the hidden layer and the weight-decay parameter to regularize the weights across neurons. These weights were then used to calculate variable importance for input features.

Estimates from all three methods were then pooled across species, and the cross-correlation and pairwise identity were assessed across methods. For the final estimate of each species, we took the "mean" estimate on the interval [1-6], though most methods agreed for most species (see Results). We suggest that future researchers may wish to conduct an explicit simulation study to compare GLM and AI/ML methods for predicting threat status, though in general we expect (and desire) strong concordance in both approaches.

Pooling the assessed and imputed statuses for all 384 species, we then tested for a relationship between ED and extinction risk across categories using the notch test on the associated bar-plot, and between threatened and non-threatened species using a two-sample $t$-test. Despite the fact that threat status (or at least, many of the underlying predictors) may exhibit strong phylogenetic signal, this is an explicitly non-phylogenetic test. Rather than an evolutionary signal, we are solely interested in whether the correlation exists at time zero given current conditions, for each species independently.

\section{Supplementary information}

Supplementary information accompanies this paper at https://doi.org/10. 1186/s12862-020-01642-3.

Additional file 1. Supplementary data.

Additional file 2. Supplementary methods and information.

Abbreviations

AET: Actual evapotranspiration; ANN: Artificial neural networks; CL: Carapace length; CR: Critically endangered; DD: Data deficient; ED: Evolutionary distinctiveness; EDGE: Evolutionarily Distinct, Globally Endangered; 
EN: Endangered; EX: Extinct; g: Grams; IUCN: International Union for Conservation of Nature; kg: Kilogram; km: Kilometer; K-Pg: CretaceousPaleogene; LC: Least concern; LRT: Likelihood ratio test; m: Meters; Ma: Million years ago; MCMC: Markov chain Monte Carlo; ML: Machine learning; MODIS: Moderate resolution imaging spectroradiometer; NPP: Net primary production; NT: Near threatened; PGLM: Phylogenetic generalized linear model; RF: Random forests; TL: Total length; UA: Unassessed; VU: Vulnerable

\section{Acknowledgments}

Computational resources were provided by the GWU ColonialOne HPC Center. We thank A. Cuff, P. Tarroso, and two anonymous reviewer for comments.

\section{Authors' contributions}

TJC, WJ and RAP conceived the study. TJC, PK and RAP generated the data, TJC and RAP performed the analyses, TJC and RAP wrote the manuscript. All authors read and commented on the final version. The authors read and approved the final manuscript.

\section{Funding}

This research was supported by US NSF grants DEB-1441737, DEB-1558568 and NSF DBI-1262600 to W.J. and DEB-1441719 to R.A.P. The authors declare NSF had no role in the design or outcome of this study.

\section{Availability of data and materials}

All data used in this study are provided either in this document, supplemental information, or in the supplemental files in DataDryad repository (https://datadryad.org/review?doi=doi:10.5061/dryad.h19t7b2).

\section{Ethics approval and consent to participate}

Not applicable.

\section{Consent for publication}

Not applicable.

\section{Competing interests}

RAP is an Associate Editor for BMC Evolutionary Biology. The authors declare that we have no other competing interests.

\section{Author details}

'Department of Biological Sciences, The George Washington University, Washington, DC 20052, USA. ${ }^{2}$ Present address: Department of Biological Science, Florida State University, Tallahassee, FL 32304, USA. ${ }^{3}$ Herndon High School, Herndon, VA 20170, USA. ${ }^{4}$ Center for Biodiversity and Global Change, Yale University, New Haven, CT 06511, USA. ${ }^{5}$ Department of Ecology and Evolutionary Biology, Yale University, New Haven, CT 06511, USA.

Received: 30 August 2019 Accepted: 17 June 2020

Published online: 10 July 2020

\section{References}

1. Vitt L, Caldwell JP. Herpetology: an introductory biology of amphibians and reptiles. 4th ed. San Diego: Academic Press; 2013.

2. Wilberg EW, Turner AH, Brochu CA. Evolutionary structure and timing of major habitat shifts in Crocodylomorpha. Sci Rep. 2019;9(1):514.

3. Sereno PC, Larsson HCE, Sidor CA, Gado B. The giant crocodyliform Sarcosuchus from the cretaceous of Africa. Science. 2001;294:1516-9.

4. Derstler K, Leitch A, Larson PL, Finsley C, Hill L. The world's largest turtles, the Vienna Archelon (4.6 $\mathrm{m}$ ) and the Dallas Protostega (4.2 m), upper cretaceous of South Dakota and Texas. JVertPaleont. 1993;13:A33.

5. Gumbs R, Gray CL, Wearn OR, Owen NR. Tetrapods on the EDGE: overcoming data limitations to identify phylogenetic conservation priorities. PLoS One. 2018;13:e0194680. https://doi.org/10.1371/journal.pone.0194680.

6. Thorbjarnarson JB, Messel H, King FW, Ross JP. Crocodiles: an action plan for their conservation. Gland: IUCN/SSC Crocodile Specialist group; 1992. p. 136.

7. Fund TC. A global action plan for conservation of tortoises and freshwater turtles. Strateg Funding Prospect. 2002;2007:30.

8. Novacek MJ. 100 million years of land vertebrate evolution: the cretaceousearly tertiary transition. Ann Missouri Bot Gard. 1999;1:230-58.
9. Brochu CA. A new late cretaceous gavialoid crocodylian from eastern North America and the phylogenetic relationships of thoracosaurs. J Vertebr Paleontol. 2004;24:610-33.

10. Nicholson DB, Holroyd PA, Benson RBJ, Barrett PM. Climate-mediated diversification of turtles in the cretaceous. Nat Commun. 2015;6:7848.

11. Ferreira GS, Bronzati M, Langer MC, Sterli J. Phylogeny, biogeography and diversification patterns of side-necked turtles (Testudines: Pleurodira). R Soc Open Sci. 2018;5:171773.

12. Markwick PJ. Fossil crocodilians as indicators of late cretaceous and Cenozoic climates: implications for using palaeontological data in reconstructing palaeoclimate. Palaeogeogr Palaeoclimatol Palaeoecol. 1998; 137:205-71.

13. MacLeod N, Rawson PF, Forey PL, Banner FT, Boudagher-Fadel MK, Bown PR, et al. The cretaceous-tertiary biotic transition. J Geol Soc Lond. 1997;154: 265-92.

14. Joyce WG. A review of the fossil record of $B=$ basal Mesozoic turtles. Bull Peabody Museum Nat Hist. 2017;58:65-113.

15. Vlachos E, Randolfe E, Sterli J, Leardi JM. Changes in the diversity of turtles (Testudinata) in South America from the late Triassic to the present. Ameghiniana. 2018;55:619.

16. Foth C, Joyce WG. Slow and steady: the evolution of cranial disparity in fossil and recent turtles. Proc R Soc Lond B Biol Sci. 2016;283:20161881.

17. Stubbs TL, Pierce SE, Rayfield EJ, Anderson PSL. Morphological and biomechanical disparity of crocodile-line archosaurs following the endTriassic extinction. Proc R Soc B Biol Sci. 2013;280:20131940.

18. Jaffe AL, Slater GJ, Alfaro ME. The evolution of island gigantism and body size variation in tortoises and turtles. Biol Lett. 2011;7:558-61.

19. Eastman JM, Alfaro ME, Joyce P, Hipp AL, Harmon LJ. A novel comparative method for identifying shifts in the rate of character evolution on trees. Evol Int J Org Evol. 2011;65:3578-89.

20. Gonzalez-del-Pliego P, Freckleton RP, Edwards DP, Koo MS, Scheffers BR, Pyron RA, et al. Phylogenetic and trait-based prediction of threat status for data-deficient amphibians. Curr Biol. 2019;29:1557-63.

21. Gaston KJ, Blackburn TM. Birds, body size and the threat of extinction. Philos Trans R Soc LondonSeries B Biol Sci. 1995;347:205-12.

22. Fritz SA, Bininda-Emonds ORP, Purvis A. Geographical variation in predictors of mammalian extinction risk: big is bad, but only in the tropics. Ecol Lett. 2009;12:538-49

23. Cardillo M, Mace GM, Jones KE, Bielby J, Bininda-Emonds ORP, Sechrest W, et al. Multiple causes of high extinction risk in large mammal species. Science. 2005;309:1239-41.

24. Böhm M, Williams R, Bramhall HR, McMillan KM, Davidson AD, Garcia A, et al. Correlates of extinction risk in squamate reptiles: the relative importance of biology, geography, threat and range size. Glob Ecol Biogeogr. 2016;25:391-405.

25. Isaac NJB, Turvey ST, Collen B, Waterman C, Baillie JEM. Mammals on the EDGE: conservation priorities based on threat and phylogeny. PLoS One. 2007;2:e296.

26. Jetz W, Thomas GH, Joy JB, Redding DW, Hartmann K, Mooers AO. Global distribution and conservation of evolutionary distinctness in birds. Curr Biol. 2014;24:919-30

27. Cooper N, Purvis A. Body size evolution in mammals: complexity in tempo and mode. Am Nat. 2010;175:727-38.

28. Jetz W, Thomas GH, Joy JB, Hartmann K, Mooers AO. The global diversity of birds in space and time. Nature. 2012;491:444-8.

29. Jetz W, Freckleton RP. Towards a general framework for predicting threat status of data-deficient species from phylogenetic, spatial and environmental information. Philos Trans R Soc B Biol Sci. 2015;370:1-10.

30. Rosauer DF, Pollock LJ, Linke S, Jetz W. Phylogenetically informed spatial planning is required to conserve the mammalian tree of life. Proc $R$ Soc $B$ Biol Sci. 2017;284:20170627.

31. Jetz W, Pyron RA. The interplay of past diversification and evolutionary isolation with present imperilment across the amphibian tree of life. Nat Ecol Evol. 2018;2:850-8.

32. Böhm M, Collen B, Baillie JEM, Bowles P, Chanson J, Cox N, et al. The conservation status of the world's reptiles. Biol Conserv. 2013;157:372-85.

33. IUCN. The IUCN red list of threatened species. Version 2018-2; 2018. 2018 Downloaded on 14 November. http://www.iucnredlist.org.

34. Tucker CM, Cadotte MW, Carvalho SB, Davies TJ, Ferrier S, Fritz SA, et al. A guide to phylogenetic metrics for conservation, community ecology and macroecology. Biol Rev. 2017;92:698-715. 
35. Rosauer DF, Mooers AO. Nurturing the use of evolutionary diversity in nature conservation. Trends Ecol Evol. 2013;28:322.

36. Bottrill MC, Joseph LN, Carwardine J, Bode M, Cook C, Game ET, et al. Is conservation triage just smart decision making? Trends Ecol Evol. 2008;23: 649-54.

37. Rhodin AGJ, Iverson JB, Bour R, Fritz U, Georges A, Shaffer HB, et al. Turtles of the world. Annoted checklist and atlas of taxonomy, synonymy, Distrubution, and conservation status. 7th ed; 2017.

38. Rhodin AGJ, Stanford CB, Van Dijk PP, Eisemberg C, Luiselli L, Mittermeier RA, et al. Global conservation status of turtles and tortoises (order Testudines). Chelonian Conserv Biol. 2018;17:135-61.

39. Bland LM, Collen BEN, Orme CDL, Bielby JON. Predicting the conservation status of data-deficient species. Conserv Biol. 2015;29:250-9.

40. Buhlmann KA, Akre TSB, Iverson JB, Karapatakis D, Mittermeier RA, Georges A, et al. A global analysis of tortoise and freshwater turtle distributions with identification of priority conservation areas. Chelonian Conserv Biol. 2009;8: 116-49.

41. Rowe CL. "The calamity of so long life": life histories, contaminants, and potential emerging threats to long-lived vertebrates. Bioscience. 2008;58 623-31.

42. van Dijk PP, Stuart BL, AGJ R. Asian turtle trade: proceedings of a workshop on conservation and trade of freshwater turtles and tortoises in Asia-Phnom Penh, Cambodia, 1-4 December 1999. Lunenburg: Chelonian Research Foundation; 2000.

43. Lutcavage ME, Plotkin P, Witherington $B$, Lutz PL. 15 human impacts on sea turtle survival. Biol Sea Turtles. 2017:1:45.

44. Davidson AD, Hamilton MJ, Boyer AG, Brown JH, Ceballos G. Multiple ecological pathways to extinction in mammals. Proc Natl Acad Sci. 2009; 106:10702-5.

45. Arregoitia LDV, Blomberg SP, Fisher DO. Phylogenetic correlates of extinction risk in mammals: species in older lineages are not at greater risk. Proc R Soc B Biol Sci. 2013;280:20131092.

46. Tonini JFR, Beard KH, Ferreira RB, Jetz W, Pyron RA. Fully-sampled phylogenies of squamates reveal evolutionary patterns in threat status. Biol Conserv. 2016;204:23-31. https://doi.org/10.1016/j.biocon.2016.03.039.

47. Pereira AG, Sterli J, Moreira FRR, Schrago CG. Multilocus phylogeny and statistical biogeography clarify the evolutionary history of major lineages of turtles. Mol Phylogenet Evol. 2017;113:59-66.

48. Oaks JR. A time-calibrated species tree of Crocodylia reveals a recent radiation of the true crocodiles. Evol Int J Org Evol. 2011;65:3285-97.

49. Venter O, Sanderson EW, Magrach A, Allan JR, Beher J, Jones KR, et al, Sixteen years of change in the global terrestrial human footprint and implications for biodiversity conservation. Nat Commun. 2016;7:12558.

50. Kehlmaier C, Graciá E, Campbell PD, Hofmeyr MD, Schweiger S, MartínezSilvestre A, et al. Ancient mitogenomics clarifies radiation of extinct Mascarene giant tortoises (Cylindraspis spp.). Sci Rep. 2019;9:17487.

51. Rodrigues JFM, Diniz-Filho JAF. Ecological opportunities, habitat, and past climatic fluctuations influenced the diversification of modern turtles. Mol Phylogenet Evol. 2016;101:352-8.

52. Guillon J-M, Guéry L, Hulin V, Girondot M. A large phylogeny of turtles (Testudines) using molecular data. Contrib Zool. 2012;81:1.

53. Thomson RC, Shaffer HB. Sparse supermatrices for phylogenetic inference: taxonomy, alignment, rogue taxa, and the phylogeny of living turtles. Syst Biol. 2010;59:42-58.

54. Barley AJ, Spinks PQ, Thomson RC, Shaffer HB. Fourteen nuclear genes provide phylogenetic resolution for difficult nodes in the turtle tree of life. Mol Phylogenet Evol. 2010;55:1189-94.

55. Yang P, Tang Y, Ding L, Guo X, Wang Y. Validity of Pelodiscus parviformis (Testudines: Trionychidae) inferred from molecular and morphological analyses. Asian Herpetol Res. 2011;2:21-9.

56. Farkas B, Ziegler T, Pham CT, Ong AV, Fritz U. A new species of Pelodiscus from northeastern Indochina (Testudines, Trionychidae). Zookeys. 2019;824:71-86.

57. Gong S, Vamberger M, Auer M, Praschag P, Fritz U. Millennium-old farm breeding of Chinese softshell turtles (Pelodiscus spp.) results in massive erosion of biodiversity. Sci Nat. 2018;105:34.

58. Upham N, Esselstyn JA, Jetz W. Ecological causes of uneven diversification and richness in the mammal tree of life. bioRxiv. 2019;1:504803.

59. Lee TM, Jetz $W$. Unravelling the structure of species extinction risk for predictive conservation science. Proc Biol Sci. 2011;278:1329-38.

60. Purvis A, Gittleman JL, Cowlishaw G, Mace GM. Predicting extinction risk in declining species. Proc R Soc LondonSeries B Biol Sci. 2000;267:1947-52.
61. Vilela B, Villalobos F, Rodríguez MÁ, Terribile LC. Body size, extinction risk and knowledge bias in New World snakes. PLoS One. 2014;9:e113429.

62. Fritz U, Branch WR, Hofmeyr MD, Maran J, Prokop H, Schleicher A, et al. Molecular phylogeny of African hinged and helmeted terrapins (Testudines: Pelomedusidae: Pelusios and Pelomedusa). Zool Scr. 2011;40:115-25.

63. Petzold A, Vargas-Ramírez M, Kehlmaier C, Vamberger M, Branch WR, Du Preez $L$, et al. A revision of African helmeted terrapins (Testudines: Pelomedusidae: Pelomedusa), with descriptions of six new species. Zootaxa. 2014;3795:523-48.

64. Stuart BL, Parham JF. Molecular phylogeny of the critically endangered Indochinese box turtle (Cuora galbinifrons). Mol Phylogenet Evol. 2004;31:164-77.

65. Spinks PQ, Thomson RC, Pauly GB, Newman CE, Mount G, Shaffer HB. Misleading phylogenetic inferences based on single-exemplar sampling in the turtle genus Pseudemys. Mol Phylogenet Evol. 2013;68:269-81.

66. Fritz U, Daniels SR, Hofmeyr MD, González J, Barrio-Amorós CL, Široký P, et al. Mitochondrial phylogeography and subspecies of the wide-ranging sub-Saharan leopard tortoise Stigmochelys pardalis (Testudines: Testudinidae)-a case study for the pitfalls of pseudogenes and GenBank sequences. J Zool Syst Evol Res. 2010;48:348-59.

67. Spinks PQ, Shaffer HB. Conservation phylogenetics of the Asian box turtles (Geoemydidae, Cuora): mitochondrial introgression, numts, and inferences from multiple nuclear loci. Conserv Genet. 2007;8:641-57.

68. Wiens JJ, Kuczynski CA, Stephens PR. Discordant mitochondrial and nuclear gene phylogenies in emydid turtles: implications for speciation and conservation. Biol J Linn Soc. 2010;99:445-61.

69. Spinks PQ, Georges A, Shaffer HB. Phylogenetic uncertainty and taxonomic re-revisions: an example from the Australian short-necked turtles (Testudines: Chelidae). Copeia. 2015;103:536-40

70. Fujita MK, Leaché AD, Burbrink FT, McGuire JA, Moritz C. Coalescent-based species delimitation in an integrative taxonomy. Trends Ecol Evol. 2012;27: 480-8.

71. Solís-Lemus C, Knowles LL, Ané C. Bayesian species delimitation combining multiple genes and traits in a unified framework. Evolution. 2015;69:492-507.

72. Praschag $P$, Ihlow F, Flecks $M$, Vamberger M, Fritz U. Diversity of north American map and sawback turtles (Testudines: Emydidae: Graptemys). Zool Scr. 2017:46:675-82.

73. Lamb T, Lydeard C, Walker RB, Gibbons JW. Molecular systematics of map turtles (Graptemys): a comparison of mitochondrial restriction site versus sequence data. Syst Biol. 1994;43:543-59.

74. Fritz U, Stuckas H, Vargas-Ramírez M, Hundsdörfer AK, Maran J, Päckert M. Molecular phylogeny of central and south American slider turtles: implications for biogeography and systematics (Testudines: Emydidae: Trachemys). J Zool Syst Evol Res. 2012;50:125-36.

75. Poulakakis N, Edwards DL, Chiari Y, Garrick RC, Russello MA, Benavides E, et al. Description of a new Galápagos giant tortoise species (Chelonoidis; Testudines: Testudinidae) from Cerro fatal on Santa Cruz island. PLoS One. 2015:10:e0138779.

76. Edwards DL, Garrick RC, Tapia W, Caccone A. Cryptic structure and niche divergence within threatened Galápagos giant tortoises from southern Isabela Island. Conserv Genet. 2014;15:1357-69.

77. Spinks PQ, Thomson RC, Zhang Y, Che J, Wu Y, Bradley SH. Species boundaries and phylogenetic relationships in the critically endangered Asian box turtle genus Cuora. Mol Phylogenet Evol. 2012;63:656-67.

78. Struijk R. A likely new natural hybrid form of "Cuora serrata" (Cuora picturata $x$ Cuora mouhotii obsti) and its finding in the wild in Phu Yen province, Vietnam. Herpetol Notes. 2016;9:73-80.

79. Longrich NR, Bhullar B-AS, Gauthier JA. Mass extinction of lizards and snakes at the cretaceous-Paleogene boundary. Proc Natl Acad Sci. 2012;109:21396-401.

80. Markwick PJ. Crocodilian diversity in space and time: the role of climate in paleoecology and its implication for understanding $\mathrm{K} / \mathrm{T}$ extinctions. Paleobiology. 1998;24:470-97.

81. Lyson TR, Bever GS, Scheyer TM, Hsiang AY, Gauthier JA. Evolutionary origin of the turtle shell. Curr Biol. 2013;23:1113-9.

82. Jouve S, Mennecart B, Douteau J, Jalil NE. Biases in the study of relationships between biodiversity dynamics and fluctuation of environmental conditions. Palaeontol Electron. 2017;20(1):1-21.

83. Mannion PD, Chiarenza AA, Godoy PL, Cheah YN. Spatiotemporal sampling patterns in the 230 million year fossil record of terrestrial crocodylomorphs and their impact on diversity. Palaeontology. 2019;62:615-37.

84. Harris G, Pimm SL. Range size and extinction risk in forest birds. Conserv Biol. 2008;22:163-71. 
85. Lande R. Genetics and demography in biological conservation. Science. 1988;241:1455-60.

86. Caldicott DGE, Croser D, Manolis C, Webb G, Britton A. Crocodile attack in Australia: an analysis of its incidence and review of the pathology and management of crocodilian attacks in general. Wilderness Environ Med. 2005;16:143-59.

87. Congdon JD, Dunham AE, Sels RCVL. Demographics of common snapping turtles (Chelydra serpentina): implications for conservation and management of long-lived organisms. Am Zool. 1994;34:397-408.

88. Roll U, Feldman A, Novosolov M, Allison A, Bauer AM, Bernard R, et al. The global distribution of tetrapods reveals a need for targeted reptile conservation. Nat Ecol Evol. 2017;1:1677-82.

89. Moll D, Moll EO. The ecology, exploitation and conservation of river turtles New York: Oxford University Press on Demand; 2004

90. Thorbjarnarson J. Crocodile tears and skins: international trade, economic constraints, and limits to the sustainable use of crocodilians. Conserv Biol. 1999;13:465-70.

91. Hoffmann M, Hilton-Taylor C, Angulo A, Böhm M, Brooks TM, Butchart SHM, et al. The impact of conservation on the status of the world's vertebrates. Science. 2010;330:1503-9.

92. Thomas GH, Hartmann K, Jetz W, Joy JB, Mimoto A, Mooers AO. PASTIS: an $R$ package to facilitate phylogenetic assembly with soft taxonomic inferences. Methods Ecol Evol. 2013;4:1011-7.

93. Eaton MJ, Martin A, Thorbjarnarson J, Amato G. Species-level diversification of African dwarf crocodiles (genus Osteolaemus): a geographic and phylogenetic perspective. Mol Phylogenet Evol. 2009;50:496-506.

94. Stamatakis A. RAXML version 8: a tool for phylogenetic analysis and postanalysis of large phylogenies. Bioinformatics. 2014;30:1312-3.

95. Ronquist F, Teslenko M, Van Der Mark P, Ayres DL, Darling A, Höhna S, et al. Mrbayes 3.2: efficient bayesian phylogenetic inference and model choice across a large model space. Syst Biol. 2012;61:539-42.

96. Ronquist F, Klopfstein S, Vilhelmsen L, Schulmeister S, Murray DL, Rasnitsyn AP. A Total-evidence approach to dating with fossils, applied to the early radiation of the hymenoptera. Syst Biol. 2012;61:973-99.

97. Rabosky DL. No substitute for real data: a cautionary note on the use of phylogenies from birth-death polytomy resolvers for downstream comparative analyses. Evolution. 2015;69:3207-16.

98. Title PO, Rabosky DL. Do macrophylogenies yield stable macroevolutionary inferences? An example from squamate reptiles. Syst Biol. 2017;66:843-56.

99. Höhna S, May MR, Moore BR. TESS: an R package for efficiently simulating phylogenetic trees and performing Bayesian inference of lineage diversification rates. Bioinformatics. 2015;32:789-91.

100. Höhna S. Fast simulation of reconstructed phylogenies under global timedependent birth-death processes. Bioinformatics. 2013:29:1367-74.

101. Landis MJ, Schraiber JG, Liang M. Phylogenetic analysis using Lévy processes: finding jumps in the evolution of continuous traits. Syst Biol. 2012;62:193-204

102. Duchen P, Leuenberger C, Szilágyi SM, Harmon L, Eastman J, Schweizer M, et al. Inference of evolutionary jumps in large phylogenies using Lévy processes. Syst Biol. 2017;66:950-63.

103. Landis MJ, Schraiber JG. Pulsed evolution shaped modern vertebrate body sizes. Proc Natl Acad Sci. 2017;114:13224-9.

104. Bland LM, Böhm M. Overcoming data deficiency in reptiles. Biol Conserv. 2016;204:16-22.

105. Lee TM, Jetz W. Future battlegrounds for conservation under global change. Proc R Soc B Biol Sci. 2008;275:1261-70.

106. Kriticos DJ, Jarošik V, Ota N. Extending the suite of bioclim variables: a proposed registry system and case study using principal components analysis. Methods Ecol Evol. 2014;5:956-60.

107. Zhao M, Heinsch FA, Nemani RR, Running SW. Improvements of the MODIS terrestrial gross and net primary production global data set. Remote Sens Environ. 2005;95:164-76.

108. Goolsby EW, Bruggeman J, Ané C. Rphylopars: fast multivariate phylogenetic comparative methods for missing data and within-species variation. Methods Ecol Evol. 2017;8:22-7

109. Shirley MH, Villanova VL, Vliet KA, Austin JD. Genetic barcoding facilitates captive and wild management of three cryptic African crocodile species complexes. Anim Conserv. 2015;18:322-30

110. Praschag P, Hundsdörfer AK, Reza A, Fritz U. Genetic evidence for wild-living Aspideretes nigricans and a molecular phylogeny of south Asian softshell turtles (Reptilia: Trionychidae: Aspideretes, Nilssonia). Zool Scr. 2007;36:30110.

111. Gerlach J, Canning L. Taxonomy of Indian Ocean giant tortoises (Dipsochelys). Chelonian Conserv Biol. 1998:3:3-19.

112. Kembel SW, Cowan PD, Helmus MR, Cornwell WK, Morlon H, Ackerly DD, et al. Picante: R tools for integrating phylogenies and ecology. Bioinformatics. 2010;26:1463-4.

113. Olden JD, Lawler JJ, Poff NL. Machine learning methods without tears: a primer for ecologists. Q Rev Biol. 2008;83:171-93.

114. Cutler DR, Edwards TC, Beard KH, Cutler A, Hess KT, Gibson J, et al. Random forests for classification in ecology. Ecology. 2007:88:2783-92.

115. Bielby J, Cardillo M, Cooper N, Purvis A. Modelling extinction risk in multispecies data sets: phylogenetically independent contrasts versus decision trees. Biodivers Conserv. 2010;19:113-27.

116. Kuhn M. Building predictive models in $\mathrm{R}$ using the caret package. J Stat Softw. 2008;28:1-26.

\section{Publisher's Note}

Springer Nature remains neutral with regard to jurisdictional claims in published maps and institutional affiliations.
Ready to submit your research? Choose BMC and benefit from:

- fast, convenient online submission

- thorough peer review by experienced researchers in your field

- rapid publication on acceptance

- support for research data, including large and complex data types

- gold Open Access which fosters wider collaboration and increased citations

- maximum visibility for your research: over $100 \mathrm{M}$ website views per year

At BMC, research is always in progress.

Learn more biomedcentral.com/submissions 